\title{
Avaliação sorológica da leptospirose e brucelose em pacientes moradores da área rural do município de Guaraci, Paraná, Brasil
}

\author{
Serologic survey for leptospirosis and brucellosis in patients from rural area in \\ Guaraci County, Parana State, Brazil
}

João Luis Garcia' e Italmar Teodorico Navarro²

\begin{abstract}
Resumo No presente estudo foram avaliadas as soropositividades para Leptospira interrogans e Brucella abortus, através das provas de soroaglutinação microscópica e aglutinação em tubo, respectivamente, em pacientes da área rural que procuraram o Posto de Saúde do município de Guaraci, Paraná, Brasil. Das 115 amostras de soros testadas, três $(2,6 \%)$ apresentaram-se sororeagentes para Leptospira spp. Com relação ao estudo sorológico da brucelose não foram verificados títulos positivos.
\end{abstract}

Palavras-chaves: Leptospirose. Brucelose. Prevalência. Leptospira interrogans. Brucella spp.

Abstract The present study evaluated patients that were attended at the Health Center of Guaraci Municipality, Paraná State, Brazil. Three (2.6\%) patients were leptospirosis positive from a total of 115 samples. No significant statistical differences were observed for risk factors. There was no positive test for brucellosis.

Key-words: leptospirosis. brucellosis. Prevalence. Leptospira interrogans. Brucella spp.

A brucelose e a leptospirose são doenças consideradas de risco ocupacional afetando principalmente açougueiros, veterinários, magarefes e trabalhadores rurais ${ }^{5}$. Existe porém a hipótese de que a leptospirose não seja inteiramente uma doença ocupacional ${ }^{1}$, associando-se mais a atividades recreativas ${ }^{2}$.

Portanto, a pesquisa de anticorpos antileptospira e antibrucela em pacientes pode fornecer indícios se há relevância dessas infecções no ambiente de moradia. Para isto o presente estudo, teve como objetivo, determinar a soropositividade para leptospirose e para brucelose em pacientes oriundos da zona rural, que procuraram a Unidade de Saúde de Guaraci, Paraná, Brasil.

Após prévia explicação sobre o trabalho aos pacientes e consentimento, as amostras sangüíneas foram colhidas no período de abril a maio de 1993, de pacientes que procuraram espontaneamente a Unidade de Saúde do município de Guaraci, Paraná. Foram colhidas um total de $115(10 \%)$ amostras de indivíduos de ambos os sexos, com idades variando de 6 a 74 anos, de uma população estimada em 1.148 habitantes da zona rural de Guaraci ${ }^{4}$.
Os soros foram submetidos a reação de soroaglutinação microscópica, para detectar anticorpos IgG antiLeptospira interrogans, utilizando-se 23 sorovares, representantes de diferentes sorogrupos. A técnica utilizada foi segundo descreve Cole et $\mathrm{al}^{3}$; a positividade foi considerada para títulos maiores que 100. Para detectar anticorpos IgG antiB. abortus os soros foram submetidos a técnica de aglutinação em tubo (sorodiagnóstico de Wright), utilizando-se antígeno brucélico de B. abortus inativados pelo calor e fenol (Biolab-Mérieux). Títulos positivos foram considerados aqueles maiores que 40 . Para verificar a associação entre os grupos estudados e dos riscos, utilizou-se o teste de exato de Fisher $(p \leq 0,05)$.

Verificou-se que das 115 amostras de soros testadas, três $(2,6 \%)$ foram soropositivos e $112(97,4 \%)$ foram soronegativos para leptospirose. Os títulos observados foram 100 (casos $n^{\circ} 12$ e 33) e 400 (casos $n^{\circ}$ 95), para o sorovar icterohaemorrhagiae e 100 (caso $n^{\circ}$ 95) e 200 (caso $n^{\circ} 33$ ) para o sorovar autunamlis.

Através dos dados epidemiológicos, verificou-se uma diferença significativa em relação aos pacientes que relataram ter auxiliado partos de animais, conforme

\footnotetext{
1. Departamento de Medicina Veterinária e Saúde Animal da Universidade de São Paulo, São Paulo, SP.

2. Departamento de Medicina Veterinária Preventiva do Centro de Ciências Agrárias da Universidade Estadual de Londrina, Londrina, PR. Suporte Financeiro: $\mathrm{CNPq}$

Endereço para correspondência: Dr. João Luis Garcia. CCA/UEL. Caixa Postal 6001, 86051-970 Londrina, PR.

Tel.: 5543 3714485; Fax: 55433714714.

e-mail:jlgarcia@usp.br

Recebido para publicação em 11/5/2000
} 
verificado pelo teste de exato de Fisher $(p=0,013)$. Não houve diferença estatística, naqueles indivíduos que relataram o hábito de consumir carnes cruas ou mal cozidas, consumo de leite cru e simples contato com animais. Também não foram verificadas diferenças significativas, com relação ao sexo $(p=0,36)$ e as faixas etárias estudadas $(p=0,57)$.

Com relação aos resultados obtidos nos exames de aglutinação em tubo para detectar anticorpos antiBrucella abortus, das 115 amostras analisadas não foram observados títulos positivos. Três indivíduos apresentaram títulos iguais a 10, que foram considerados como reações inespecíficas.
Através do inquérito epidemiológico, verificou-se uma diferença significativa naqueles indivíduos que relataram auxílio a partos em animais. Esses resultados podem sugerir que indivíduos que mantenham contato íntimo com animais, estejam mais expostos à infeção, o que também é relatado por outros autores ${ }^{25}$.

Resultados do presente trabalho sugerem que a população da zona rural encontra-se exposta à infecção por leptospiras, e que o auxílio a partos em animais pode ser um fator de risco. Portanto, uma maior vigilância por parte das autoridades sanitárias deve ser implementada.

\section{REFERÊNCIAS BIBLIOGRÁFICAS}

1. Andrade J, Brandão A. Contribuição ao conhecimento da epidemiologia da leptospirose humana, com especial referência ao Grande Rio, Brasil, no período de 1970 a 1982. Memorando do Instituto Oswaldo Cruz 82: 91-100,1987.

2. Almeida LP, Martins LFS, Brod CS, Germano PML. Levantamento soroepidemiologico de leptospirose em trabalhadores do serviço de saneamento ambiental em localidade urbana da região sul do Brasil. Revista de Saúde Pública 28:76-81, 1994.

3. Cole JR, Suilzer CR, Pursell AR. Improved microtechnique for the leptospiral Microscopic agglutination test application. Microbiology 25:970-980, 1973.
4. Instituto Brasileiro de Geografia e Estatística (IBGE). Censo Demográfico: resultados do universo relativos às características da população e dos domicílios, Paraná. Instituto Brasileiro de Geografia e Estastística, Rio de Janeiro 22, 1991.

5. Vasconcelos LM, Ramos-Vieira MN, Osório-Cisalpino E, Cota-Koury M. Pesquisa de aglutininas antiLeptospira em trabalhadores da localidade de Londrina-Paraná, Brasil. Revista Latino Americana de Microbiologia 35:153-157, 1993. 